ENCYCLOPÉDIE Encyclopédie berbère

BERBERE

$10 \mid 1991$

10 | Beni Isguen - Bouzeis

\title{
Beni Isguen
}

\section{Y. Bonête}

\section{OpenEdition}

Journals

Édition électronique

URL : http://journals.openedition.org/encyclopedieberbere/1676

DOI : 10.4000/encyclopedieberbere.1676

ISSN : 2262-7197

\section{Éditeur}

Peeters Publishers

\section{Édition imprimée}

Date de publication : 1 décembre 1991

Pagination : 1451-1452

ISBN : 2-85744-549-0

ISSN : 1015-7344

Référence électronique

Y. Bonête, «Beni Isguen », Encyclopédie berbère [En ligne], 10 | 1991, document B60, mis en ligne le 01 mars 2013, consulté le 24 septembre 2020. URL : http://journals.openedition.org/ encyclopedieberbere/1676; DOI : https://doi.org/10.4000/encyclopedieberbere.1676

Ce document a été généré automatiquement le 24 septembre 2020

(c) Tous droits réservés 


\section{Beni Isguen}

\section{Y. Bonête}

1 Ville du Mzab (Algérie) à $600 \mathrm{~km}$ au sud d'Alger. Au contraire des autres villes de la pentapole mozabite, Beni Isguen n'est pas construite sur un piton rocheux mais sur le flan d'une colline rocheuse et c'est aussi la seule ville de la pentapole à ne pas avoir été bâtie sur l'oued M'zab mais au confluent de l'ouest N'tizza et de l'oued Mzab ce qui a permis aux fondateurs d'implanter la palmeraie (le jardin nourricier de la ville) en amont de l'oued N'tissas, oued essentiellement souterrain sauf en période de crue. Le choix de cet emplacement et l'érection de la ville n'est pas nécessairement antérieur à la création de Ghardaïa comme cela a souvent été écrit, sans que des références puissent être avancées. Comme on le verra plus loin une autre ville (Tafilelt) a peut-être été antérieure à Beni Isguen. Au cours des siècles la charge d'occupation des sols par les palmeraies et leur exploitation intensive a, peu à peu, asséché le cours souterrain de l'oued Mzab; l'édification de Bou Noura, Melika et Ghardaïa ne s'explique pas autrement que par la recherche de puits exploitables en remontant l'oued vers l'amont.

2 La réputation de ville sainte qui est faite depuis quelques décennies à Beni Isguen est assez récente car en 1860 encore c'est Melika qui était considérée comme la ville sainte du Mzab tandis que Beni Isguen passait pour être la cité militaire de la confédération mozabite. En ce temps là (1860), le haut de la colline de Beni Isguen était couvert de ruines, mosquée comprise, et se trouvait en dehors des murailles de la ville habitée. Puis la partie haute de la colline fut reconstruite et incluse dans la ville de Beni Isguen mais la cour de l'ancienne mosquée (dite "mosquée de Tafilelt») fut conservée et est toujours entretenue. Si une guerre a opposé Tafilelt et Beni Isguen à un moment de leur histoire, Tafilelt l'a apparemment perdue et ses habitants ont peut-être émigré vers d'autres cités du Mzab comme cela est raconté au sujet de la vieille ville de Bou Noura en ruine sur le sommet de la colline au flanc de laquelle se trouve l'actuelle ville de Bou Noura.

3 Au XIX $x^{e}$ siècle, la ville comportait deux murailles d'enceinte espacées de moins de dix mètres. Toutes les portes de ces deux enceintes étaient fermées la nuit mais l'espace entre les murailles permettaient aux nomades (qui ne sont pas Ibadites) commerçant avec les citadins de rester à l'abri de la muraille extérieure. 


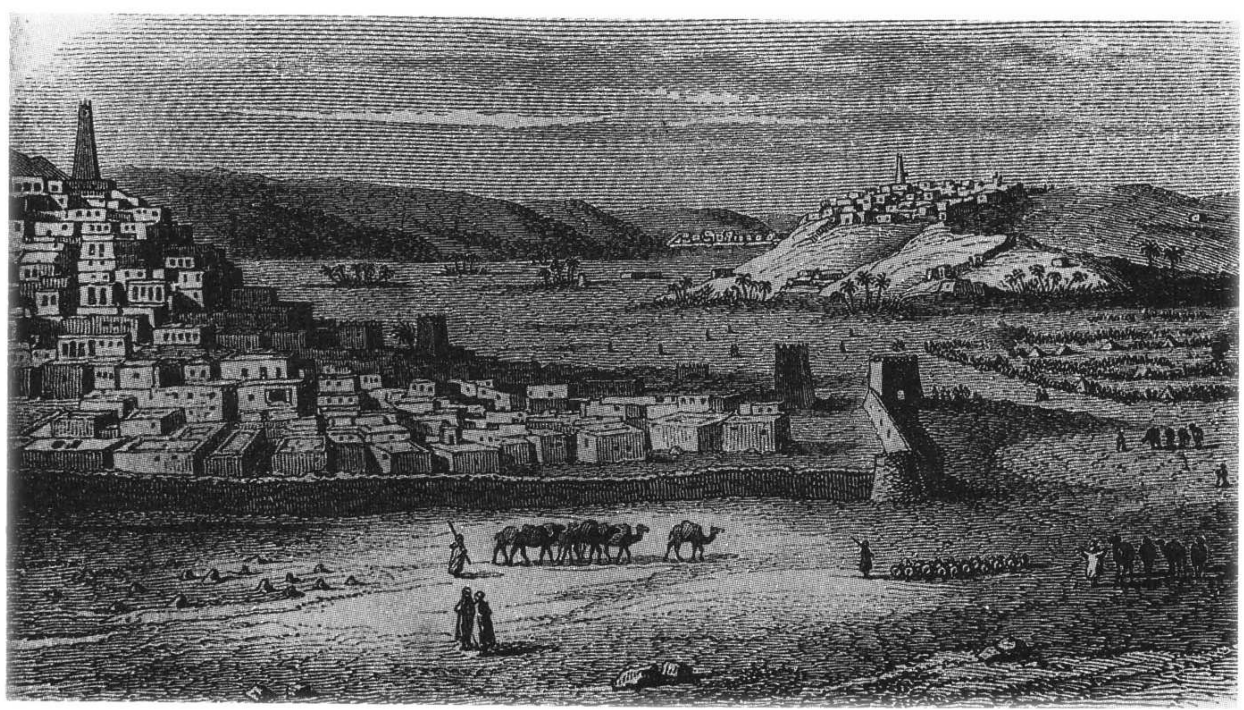

Beni Isguen, Melika et Ghardaïa en 1854.

4 L'insécurité ayant disparue avec l'annexion du Mzab par la France (1882) la cité s'agrandit et supprima la muraille extérieure. La nouvelle enceinte, toujours visible aujourd'hui, fut construite vers 1870 . Cette enceinte est bien entretenue et il est difficile de repérer toute trace d'extension. Cela pour rappeler que toute ambition de datation par un examen superficiel des bâtisses est assez vaine. Quoiqu'il en soit, après que Beni Isguen et Tafilelt ne firent plus qu'une seule ville, que la ville haute fut reconstruite à l'intérieur de la nouvelle enceinte et que la mosquée du haut perdit totalement son minaret il est probable que la nécessité de maintenir un point haut de surveillance conduisit les habitants d'alors à construire une tour de guet, tout en haut $\mathrm{du}$ flanc de la colline, pour assurer la surveillance vers le plateau; de nos jours, cette tour sert de belvédère aux touristes.

5 Comme dans chaque ville de la pentapole, des lois coutumières réglementent la vie de la cité et, par exemple, les non-Ibâdites ne peuvent être propriétaires ou même simplement locataires à l'intérieur de la ville. Toutefois, sous la poussée du développement moderne Beni Isguen a largement débordé hors de ses murailles, tout comme les autres villes du Mzab.

\section{BIBLIOGRAPHIE}

DELHEURE J., Faits et dires du Mzab, Sellaf, Coll. Études ethnolinguistiques Maghreb-Sahara S. Chaker, M. Gast, direct. $n^{\circ} 4,1986,332$ p.

DONNADIEU C. et P., DIDILLON H. et J.-M., Habiter le désert, les maisons mzabites, Architecture et recherches, Bruxelles, Mardaga, 1986, 254 p. 
RAVEREAU A., Le Mzab, une leçon d'architecture, Sindbad, Paris, 1981, 282 p.

TRISTRAM H.-B., The great Sahara: Wanderings south of the Atlas mountains, Londres, 1860, John Murray, $435 \mathrm{p}$.

INDEX

Mots-clés : Religion, Sahara, Villes 